\title{
CD40 Ligand Deficiency
}

National Cancer Institute

\section{Source}

National Cancer Institute. CD40 Ligand Deficiency. NCI Thesaurus. Code C61244.

Patients with the X-linked hyper Ig M syndrome have a deficiency of a protein, CD40

lig and that is found on the surface of T-lymphocytes. As a consequence of the deficiency of this protein, their T-lymphocytes are unable to instruct B-lymphocytes to switch their production of gamma globulins from Ig M to IgG and IgA. As a result, patients have decreased levels of IgG and IgA and normal or elevated levels of IgM. In addition, since CD40 ligand is important to other functions of T-lymphocytes, they also have a defect in some of the protective functions of their T-lymphocytes. 